\title{
Fuzzy Feedforward and Feedback Control Method Based On Long Time Delay Systems
}

\author{
Honge Ren ${ }^{1,2}$, Yali Chen ${ }^{1}$ and Ming Yu ${ }^{1,2 *}$ \\ ${ }^{1}$ College of Information and Computer Engineering, Northeast Forestry \\ University, Harbin, Heilongjiang, 150040, China \\ ${ }^{2}$ Forestry Intelligent Equipment Engineering Research Center, Harbin, \\ Heilongjiang, 150040, China \\ nefu_rhe@163.com,cyl_1005@126.com,*yuming@nefu.edu.cn
}

\begin{abstract}
Aiming at some system of nonlinear, large delay, large inertia control problem, on the analysis of fuzzy control, the feedforward feedback control and PID control performance, this article proposes a fuzzy control in combination with feedforward feedback control method, to solve the shortcomings of conventional feedforward feedback methods. By using the fuzzy control to realize PID parameters adaptive adjustment online, combining with feedforward control and PID feedback control to eliminate the interference of the system, and the simulation is carried out in Matlab/Simulink environment. Simulation results verify the feasibility and effectiveness of this method, in the overshoot of the system and adjusting time and anti-jamming ability and multiple aspects have the advantage compared with the conventional feedforward and feedback approach, with satisfactory control effect.
\end{abstract}

Keywords: fuzzy PID control, feedforward and feedback, long time-delay

\section{Introduction}

At present, many systems are nonlinear, long time-delay, large inertia characteristics, it is difficult to obtain precise mathematical model [1]. The conventional PID control system is simple in structure, convenient in use, has good control effect in the condition of linear characteristic and parameter matching well. Once the deviation from the operating point is far, or parameters changes or the existence of interference, the conventional PID controller parameters can not be changed, the system is difficult to guarantee it's dynamic quality and has great limitations. Therefore, it is difficult to meet the control requirements of the complex system using the conventional PID control method [2]. In order to improve the performance of the system, make it have better adaptive ability and robustness, a variety of control methods need to be combined, combined with the advantages of each method to improve the dynamic response of the system. Literature [3], proposed a kind of generalized predictive control method with fuzzy reasoning combined with predictive control based on the numerical control method, to improve the position servo system dynamic performance and robustness, but the calculation is complicated. Literature [4], using OPT optimization strategy to improve Smith Predictor Control. Deduced the second-order system disturbance compensation formula, through negative feedback to eliminate the influence of system parameters uncertainty and system lag link. But the PID control parameters can't be dynamically adjusted, once the parameter changes, unable to meet the demand for high precision and high performance. Literature [5], in view of the greenhouse control system put forward PID control combine with neural network 
control and it's improvement control method, to make up the problem of parameter tuning is difficult to complete and the effect is not ideal. But the search for optimal process is more complex. Literature [6], on the basis of conventional synovial variable structure method, combine the neural PID control method, make full use of the advantages of both, provides a strong robustness of nonlinear control strategy, but the speed of BP algorithm is slow and there is minimum problems.

In view of the existence of the above problems, this article proposes the fuzzy control in combination with feedforward feedback control. Feedback control using the simple PID control, it has simple algorithm, small amount of calculation [7-8]. With Matlab/Simulink simulation experiments, compared with conventional feedforward feedback method to verify the performance of this method.

\section{The Conventional Control Method}

\subsection{PID Control Method}

The bolck diagram of the conventioanl PID control system is shown in Figure 1 [9]:

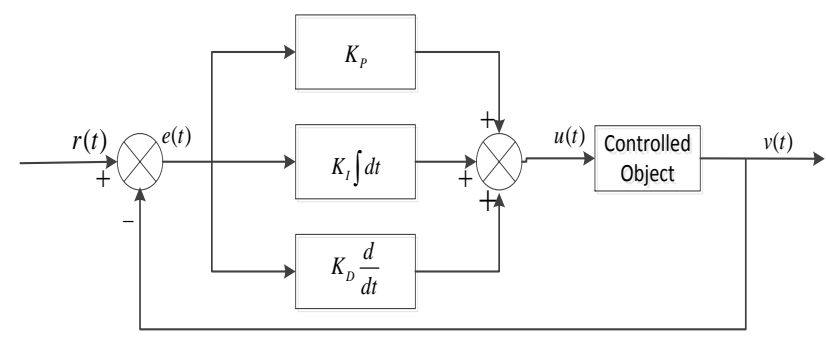

Figure 1. Principle Block Diagram of PID Control System

The expression of PID control algorithm is:

$$
u(t)=K_{P} e(t)+K_{I} \int e(t) d t+K_{D} \frac{d e(t)}{d t}
$$

Among them: $K_{P}$ for the proportion coefficient; $K_{I}$ for integral coefficient; $K_{D}$ for differential coefficient.

PID control algorithm has a small amount of calculation, good real-time and easy to implement. For the accurate mathematical model of the system as long as the proper selection of the appropriate controller parameters $K_{P} 、 K_{I} 、 K_{D}$ values, can satisfy the performance index of control system [10]. But the contradiction between dynamic and static performance of these fixed parameters as well as the contradiction between the setpoint and disturbance rejection can not be taken into account the system controller. So for the system of time-varying is difficult to obtain the precise mathematical, it requires the three parameters of the PID with adaptive function, which is the conventional PID control system's limitation.

\subsection{Parameter Self-Tuning Fuzzy PID Control Method}

Fuzzy control is a kind of computer control technology based on natural language control rules and fuzzy logic reasoning, it does not depend on the mathematical model of the control system, so the fuzzy control method can be used to adjust PID's three parameters online to solve the problem of poor adaptability of the PID model [11]. Selftuning fuzzy PID control system use the controlled variables error $e$ and error change rate $e c$ as the input of fuzzy systems, using the fuzzy rules made by experts and summed up 
in practice to adjust PID's three parameters online, get the parameters variation $\Delta K_{P}$ 、 $\Delta K_{I} 、 \Delta K_{D}$, plus the initial setting value of the PID controller, and then through the PID controller to act on controlled object. Fuzzy self-tuning PID control system structure as shown in Figure 2 [12].

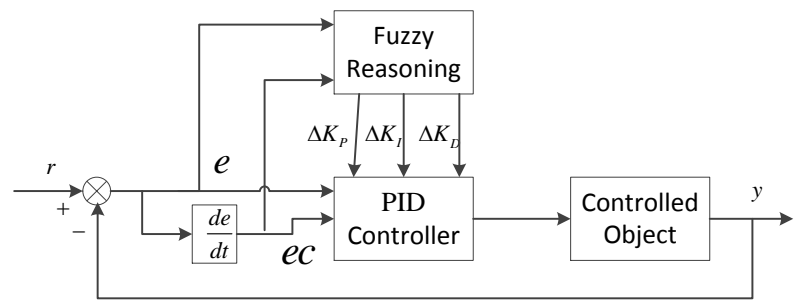

Figure 2. Structure Diagram of Parameter Self-Tuning Fuzzy PID Controller

The Parameters Of Fuzzy PID Controller Are Calculated By The Following Methods:

$K_{P}=K_{P}^{\prime}+\Delta K_{P}$

$K_{I}=K_{I}^{\prime}+\Delta K_{I}$

$K_{D}=K_{D}^{\prime}+\Delta K_{D}$

Among them: $K_{P}{ }^{\prime} 、 K_{I}{ }^{\prime} 、 K_{D}{ }^{\prime}$ for the initial value of the PID controller, set by the experience.

\section{Fuzzy Feedforward Feedback Control Method}

Figure 3 shows the structure of the fuzzy feedfoward feedback system:

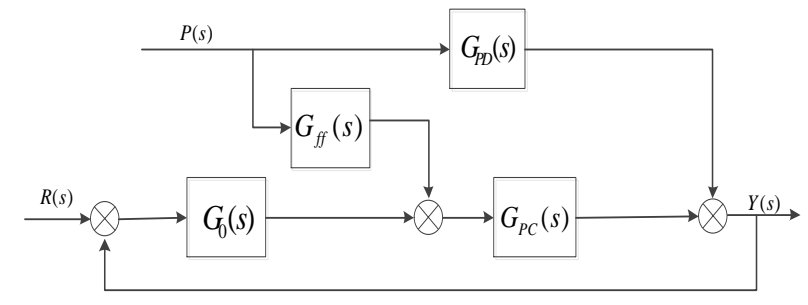

Figure 3. Structure Diagram of Fuzzy Feedforward Feedback System

Among them: $G_{0}(s)$ for fuzzy controller; $P(s)$ for measurable disturbance; $G_{P C}(s)$ for the transfer function of the control channel; $G_{P D}(s)$ for the transfer function of the interference channel; $G_{f f}(s)$ for feedforward compensation.

From Figure 3 we can see that when the system appears to interfere with $P(s)$, if only closed-loop feedback control cannot eliminate the interference quickly, make the system error becomes larger, the control effect is not ideal. Therefore, a feedforward control can be added to the feedback system, which will directly affect the control system before the interference occurs and reduce the interference to the system in a timely manner. It can be obtained the closed-loop transfer function from the figure that interference $P(s)$ to the controlled amount of $Y(s)$ is:

$$
\frac{Y(s)}{P(s)}=\frac{G_{P D}(s)}{1+G_{0}(s) G_{P C}(s)}+\frac{G_{f f}(s) G_{P C}(s)}{1+G_{0}(s) G_{P C}(s)}
$$


Application of non deformation condition [13]: $P(s) \neq 0 、 Y(s) \equiv 0$, bring it to the formula (5) get the transfer function of the feedforward controller is: $G_{P D}(s)+G_{f f}(s) G_{P C}(s)=0$

$$
\text { Namely: } G_{f f}(s)=-\frac{G_{P D}(s)}{G_{P C}(s)}
$$

By the formula (6) we can know that when the load or working condition change, the model will be changed, so the feedback loop is added to compensate. Since the feedforward controller appears before the deviation occurs and it mainly acts on the controlled object, can assume most of the control quantity; feedback appears after error occurs, the remaining deviation will be eliminated by the feedback control and reduce the feedforward control accuracy requirement for the model. It not only plays the characteristics of fast compensation of feedforward controller, but also can get the stability control precision, and has a certain adaptive capacity. The parameters' adjustment rules of the fuzzy controller $G_{0}(s)$ is based on the operation experience summary and data processing. According to the theoretical analysis, the following relations can be concluded between the error $e$ and the error change rate $e c$ and the output parameter correction quantity $\Delta K_{P} 、 \Delta K_{I} 、 \Delta K_{D}$ [14]:

(1) When $|e(t)|$ is larger, to speed up the response of the system, it should take a larger $K_{P}$, so that the time constant and damping coefficient of the system will be reduced. May not be too large, otherwise it will lead to instability of the system; in order to avoid the system may cause the over-range control effect at the beginning, should take the smaller $K_{D}$, to speed up the system response; in order to avoid the large overshoot, can remove the integral function, take $K_{I}=0$.

(2) When $|e(t)|$ is in the middle size, you should take the smaller $K_{P}$, which make the system overshoot is smaller; at this time the value of $K_{D}$ is more critical to the system, in order to ensure the system's response speed, value $K_{D}$ should be appropriate; it may be appropriate to add a little $K_{I}$, but not too large.

(3) When $|e(t)|$ is smaller, to make the system has good steady-state performance, it is desirable to larger $K_{P}$ and $K_{I}$; in order to avoid the system's shock at the equilibrium point, the value of $K_{D}$ should be appropriate.

Based on the above relationship between the input variables and output variables, considering the influence of the variation rate of $|e c(t)|$, combined with the literature [15] get Table 1-3 of the fuzzy control rules table as follows:

Table 1. Fuzzy Control Rules of $\Delta K_{P}$

\begin{tabular}{cccccccc}
\hline $\mathrm{e}$ & $\mathrm{N}$ & $\mathrm{N}$ & $\mathrm{N}$ & $\mathrm{Z}$ & $\mathrm{P}$ & $\mathrm{P}$ & $P$ \\
$\mathrm{e}$ & $\mathrm{B}$ & $\mathrm{M}$ & $\mathrm{S}$ & $\mathrm{O}$ & $\mathrm{S}$ & $\mathrm{M}$ & $B$ \\
\hline $\mathrm{N}$ & $\mathrm{P}$ & $\mathrm{P}$ & $\mathrm{P}$ & $\mathrm{P}$ & $\mathrm{P}$ & $\mathrm{Z}$ & $\mathrm{Z}$ \\
$\mathrm{B}$ & $\mathrm{B}$ & $\mathrm{B}$ & $\mathrm{M}$ & $\mathrm{M}$ & $\mathrm{S}$ & $\mathrm{O}$ & $O$ \\
$\mathrm{~N}$ & $\mathrm{P}$ & $\mathrm{P}$ & $\mathrm{P}$ & $\mathrm{P}$ & $\mathrm{P}$ & $\mathrm{Z}$ & $N$ \\
$\mathrm{M}$ & $\mathrm{B}$ & $\mathrm{B}$ & $\mathrm{M}$ & $\mathrm{S}$ & $\mathrm{S}$ & $\mathrm{O}$ & $S$ \\
$\mathrm{~N}$ & $\mathrm{P}$ & $\mathrm{P}$ & $\mathrm{P}$ & $\mathrm{P}$ & $\mathrm{Z}$ & $\mathrm{N}$ & $N$ \\
$\mathrm{~S}$ & $\mathrm{M}$ & $\mathrm{M}$ & $\mathrm{M}$ & $\mathrm{S}$ & $\mathrm{O}$ & $\mathrm{S}$ & $S$
\end{tabular}




\begin{tabular}{cccccccc}
$\mathrm{Z}$ & $\mathrm{P}$ & $\mathrm{P}$ & $\mathrm{P}$ & $\mathrm{Z}$ & $\mathrm{N}$ & $\mathrm{N}$ & $N$ \\
$\mathrm{O}$ & $\mathrm{M}$ & $\mathrm{M}$ & $\mathrm{S}$ & $\mathrm{O}$ & $\mathrm{S}$ & $\mathrm{M}$ & $M$ \\
$\mathrm{P}$ & $\mathrm{P}$ & $\mathrm{P}$ & $\mathrm{Z}$ & $\mathrm{N}$ & $\mathrm{N}$ & $\mathrm{N}$ & $N$ \\
$\mathrm{~S}$ & $\mathrm{~S}$ & $\mathrm{~S}$ & $\mathrm{O}$ & $\mathrm{S}$ & $\mathrm{S}$ & $\mathrm{M}$ & $M$ \\
$\mathrm{P}$ & $\mathrm{P}$ & $\mathrm{Z}$ & $\mathrm{N}$ & $\mathrm{N}$ & $\mathrm{N}$ & $\mathrm{N}$ & $N$ \\
$\mathrm{M}$ & $\mathrm{S}$ & $\mathrm{O}$ & $\mathrm{S}$ & $\mathrm{M}$ & $\mathrm{M}$ & $\mathrm{M}$ & $B$ \\
$P$ & $Z$ & $Z$ & $N$ & $N$ & $N$ & $N$ & $N$ \\
$B$ & $O$ & $O$ & $M$ & $M$ & $M$ & $B$ & $B$ \\
\hline
\end{tabular}

Table 2. Fuzzy Control Rules of $\Delta K_{I}$

\begin{tabular}{cccccccc}
\hline $\mathrm{e}$ & $\mathrm{N}$ & $\mathrm{N}$ & $\mathrm{N}$ & $\mathrm{Z}$ & $\mathrm{P}$ & $\mathrm{P}$ & $P$ \\
$\mathrm{c}$ & $\mathrm{B}$ & $\mathrm{M}$ & $\mathrm{S}$ & $\mathrm{O}$ & $\mathrm{S}$ & $\mathrm{M}$ & $B$ \\
\hline $\mathrm{N}$ & $\mathrm{N}$ & $\mathrm{N}$ & $\mathrm{N}$ & $\mathrm{N}$ & $\mathrm{N}$ & $\mathrm{Z}$ & $Z$ \\
$\mathrm{~B}$ & $\mathrm{~B}$ & $\mathrm{~B}$ & $\mathrm{M}$ & $\mathrm{M}$ & $\mathrm{S}$ & $\mathrm{O}$ & $O$ \\
$\mathrm{~N}$ & $\mathrm{~N}$ & $\mathrm{~N}$ & $\mathrm{~N}$ & $\mathrm{~N}$ & $\mathrm{~N}$ & $\mathrm{Z}$ & $Z$ \\
$\mathrm{M}$ & $\mathrm{B}$ & $\mathrm{B}$ & $\mathrm{M}$ & $\mathrm{S}$ & $\mathrm{S}$ & $\mathrm{O}$ & $O$ \\
$\mathrm{~N}$ & $\mathrm{~N}$ & $\mathrm{~N}$ & $\mathrm{~N}$ & $\mathrm{~N}$ & $\mathrm{Z}$ & $\mathrm{P}$ & $P$ \\
$\mathrm{~S}$ & $\mathrm{~B}$ & $\mathrm{M}$ & $\mathrm{S}$ & $\mathrm{S}$ & $\mathrm{O}$ & $\mathrm{S}$ & $S$ \\
$\mathrm{Z}$ & $\mathrm{N}$ & $\mathrm{N}$ & $\mathrm{N}$ & $\mathrm{Z}$ & $\mathrm{P}$ & $\mathrm{P}$ & $P$ \\
$\mathrm{O}$ & $\mathrm{M}$ & $\mathrm{M}$ & $\mathrm{S}$ & $\mathrm{O}$ & $\mathrm{S}$ & $\mathrm{M}$ & $M$ \\
$\mathrm{P}$ & $\mathrm{N}$ & $\mathrm{N}$ & $\mathrm{Z}$ & $\mathrm{P}$ & $\mathrm{P}$ & $\mathrm{P}$ & $P$ \\
$\mathrm{~S}$ & $\mathrm{M}$ & $\mathrm{S}$ & $\mathrm{O}$ & $\mathrm{S}$ & $\mathrm{S}$ & $\mathrm{M}$ & $B$ \\
$\mathrm{P}$ & $Z$ & $\mathrm{Z}$ & $\mathrm{P}$ & $\mathrm{P}$ & $\mathrm{P}$ & $\mathrm{P}$ & $P$ \\
$\mathrm{M}$ & $O$ & $\mathrm{O}$ & $\mathrm{S}$ & $\mathrm{S}$ & $\mathrm{M}$ & $\mathrm{B}$ & $B$ \\
$P$ & $Z$ & $Z$ & $P$ & $P$ & $P$ & $P$ & $P$ \\
$B$ & $O$ & $O$ & $S$ & $M$ & $M$ & $B$ & $B$ \\
\hline
\end{tabular}

Table 3. Fuzzy Control Rules of $\Delta K_{D}$

\begin{tabular}{cccccccc}
\hline $\mathrm{e}$ & $\mathrm{N}$ & $\mathrm{N}$ & $\mathrm{N}$ & $\mathrm{Z}$ & $\mathrm{P}$ & $\mathrm{P}$ & $P$ \\
$\mathrm{e}$ & $\mathrm{B}$ & $\mathrm{M}$ & $\mathrm{S}$ & $\mathrm{O}$ & $\mathrm{S}$ & $\mathrm{M}$ & $B$ \\
$\mathrm{c}$ & & & & & & & \\
\hline $\mathrm{N}$ & $\mathrm{P}$ & $\mathrm{N}$ & $\mathrm{N}$ & $\mathrm{N}$ & $\mathrm{N}$ & $\mathrm{N}$ & $P$ \\
$\mathrm{~B}$ & $\mathrm{~S}$ & $\mathrm{~S}$ & $\mathrm{~B}$ & $\mathrm{~B}$ & $\mathrm{~B}$ & $\mathrm{M}$ & $S$ \\
$\mathrm{~N}$ & $\mathrm{P}$ & $\mathrm{N}$ & $\mathrm{N}$ & $\mathrm{N}$ & $\mathrm{N}$ & $\mathrm{N}$ & $Z$ \\
$\mathrm{M}$ & $\mathrm{S}$ & $\mathrm{S}$ & $\mathrm{B}$ & $\mathrm{M}$ & $\mathrm{M}$ & $\mathrm{S}$ & $O$ \\
$\mathrm{~N}$ & $\mathrm{Z}$ & $\mathrm{N}$ & $\mathrm{N}$ & $\mathrm{N}$ & $\mathrm{N}$ & $\mathrm{N}$ & $Z$ \\
$\mathrm{~S}$ & $\mathrm{O}$ & $\mathrm{S}$ & $\mathrm{M}$ & $\mathrm{M}$ & $\mathrm{S}$ & $\mathrm{S}$ & $O$ \\
$\mathrm{Z}$ & $\mathrm{Z}$ & $\mathrm{N}$ & $\mathrm{N}$ & $\mathrm{N}$ & $\mathrm{N}$ & $\mathrm{N}$ & $Z$ \\
$\mathrm{O}$ & $\mathrm{O}$ & $\mathrm{S}$ & $\mathrm{S}$ & $\mathrm{S}$ & $\mathrm{S}$ & $\mathrm{S}$ & $O$ \\
$\mathrm{P}$ & $\mathrm{Z}$ & $\mathrm{Z}$ & $\mathrm{Z}$ & $\mathrm{Z}$ & $Z$ & $Z$ & $Z$ \\
$\mathrm{~S}$ & $\mathrm{O}$ & $\mathrm{O}$ & $\mathrm{O}$ & $\mathrm{O}$ & $O$ & $O$ & $O$ \\
$\mathrm{P}$ & $\mathrm{P}$ & $\mathrm{N}$ & $\mathrm{P}$ & $\mathrm{P}$ & $\mathrm{P}$ & $\mathrm{P}$ & $P$ \\
$\mathrm{M}$ & $\mathrm{B}$ & $\mathrm{S}$ & $\mathrm{S}$ & $\mathrm{S}$ & $\mathrm{S}$ & $\mathrm{S}$ & $B$ \\
$P$ & $P$ & $P$ & $P$ & $P$ & $P$ & $P$ & $P$ \\
$B$ & $B$ & $M$ & $M$ & $M$ & $S$ & $S$ & $B$ \\
\hline & & & & & & &
\end{tabular}




\section{System Simulation Experiment}

In the fuzzy adaptive controller, the controlled amount of the error $e$ and the change of the error $e c$ as the input of the fuzzy controller, $\Delta K_{P} 、 \Delta K_{I} 、 \Delta K_{D}$ as the output. This article takes the basic domain of $e$ as $[-1,1]$, and quantify it to $\{-6,6\}$; takes the basic domain of $e c$ as $[-0.02,0.02]$, and quantify it to $\{-0.18,0.18\}$; takes the basic domain of $\Delta K_{P}$ as $[-0.003,0.003]$, and quantify it to $\{-0.003,0.003\}$; takes the basic domain of $\Delta K_{I}$ as $[-0.009,0.009]$, and quantify it to $\{-3,3\}$; takes the basic domain of $\Delta K_{D}$ as $[-0.009,0.009]$, and quantify it to $\{-0.9,0.9\}$. The fuzzy sets of the input variable error $e$ and the error change rate $e c$ and the output correction $\Delta K_{P} 、 \Delta K_{I} 、 \Delta K_{D}$ are defined as \{negative big, negative middle, negative small, zero, positive small, positive middle, positive big $\}$, abbreviated as $\{\mathrm{NB}, \mathrm{NM}, \mathrm{NS}, \mathrm{ZO}, \mathrm{PS}, \mathrm{PM}, \mathrm{PB}\}$, input and output variable membership functions adopt the higher sensitivity triangle, fuzzy controller using Mamdani method.

For time-delay systems, mostly adopt the first-order inertia link to simulink, the transfer function can be expressed as:

$$
G(s)=\frac{K}{T s+1} e^{-\tau s}
$$

Among them: $K$ is the amplification factor; $T$ is the time constant; $\tau$ is the time delay of the system.

In this article, the three parameters of PID are adjusted by the conventional ZieglerNichols tuning method combined with repeated experiments, they are: $K_{P}=0.5$ 、

$K_{I}=0.01 、 K_{D}=4$; with the formula (7) as the transfer function of the delay system, combine with the literature [16] to choose the parameters in the control channel are: $K=0.38 、 T=130 、 \tau=90$, in this case the transfer function of the control channel is: $G_{P C}=\frac{0.38}{130 s+1} e^{-90 s}$, now $\frac{\tau}{T}=0.69>0.5$, can be regarded as a long time delay system; take interference channel function $K=1.2 、 T=4.5 、 \tau=93$, in this case the transfer function of the interference channel is: $G_{P D}=\frac{1.2}{4.5 s+1} e^{-93 s}$; by the formula (6) can be calculated feedforward compensation of the system is: $G_{f f}(s)=-\frac{G_{P D}(s)}{G_{P C}(s)}=\frac{156 s+1.2}{1.71 s+0.38}$.

\section{Simulation Results and Analysis}

In order to verify the function of fuzzy control in feedforward feedback, fuzzy rules of Table 1-3 are taken for the comparative experiments between fuzzy feedforward feedback and ordinary feedforward feedback, this article carries out system simulation with Matlab/Simulink respectively. The horizontal coordinate is the system simulation time, and the vertical coordinate is the simulation output value of the current time of the system in the diagram. In this article, it takes the unit step signal as the input signal of the system. Figure 4 added value of 1-2 square wave signal during the 2400-3000s, Figure 5 superimposed value of 1-2 interference at input during the 2500-3000s, the simulation time is 5000s. The simulation results obtained are shown in Figure 4-5: 


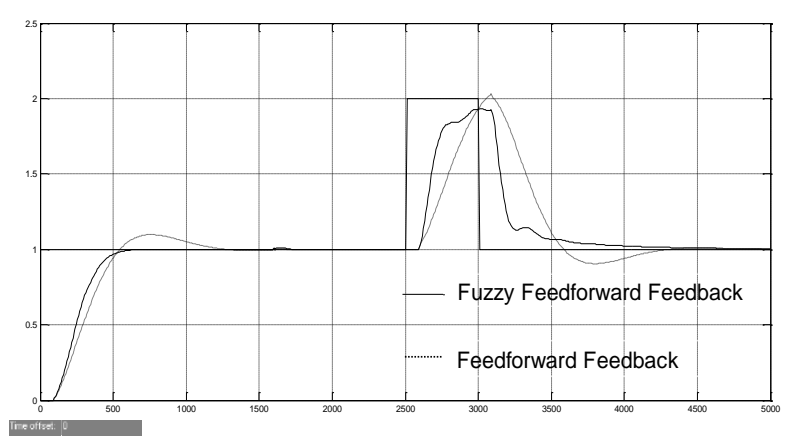

Figure 4. Schematic Diagram of System Simulation(1)

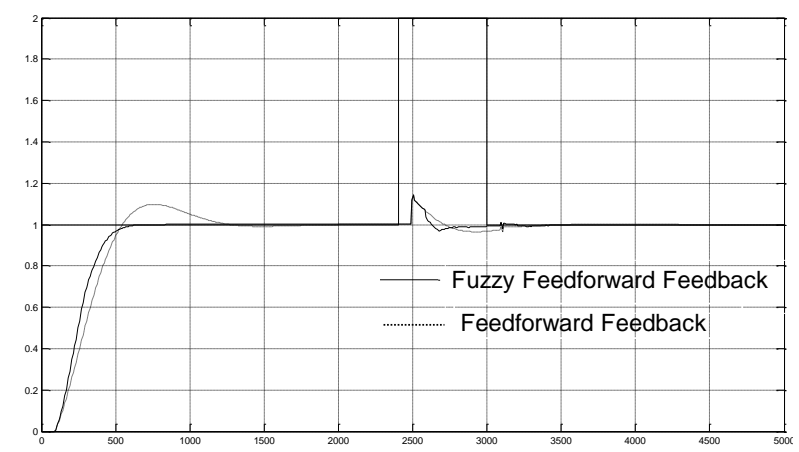

Figure 5. Schematic Diagram of System Simulation(2)

Table 4. Feature Comparison Table of Figure 4

\begin{tabular}{cccccc}
\hline & $\begin{array}{c}\text { Adjusting } \\
\text { time }\end{array}$ & overshoot & $\begin{array}{l}\text { Rising } \\
\text { rate }\end{array}$ & $\begin{array}{c}\text { The time } \\
\text { and value of } \\
\text { the lowest after } \\
\text { the interference }\end{array}$ & $\begin{array}{c}\text { The } \\
\text { balance of } \\
\text { time after the } \\
\text { interference }\end{array}$ \\
\hline $\begin{array}{c}\text { Fuzzy } \\
\text { feedforward } \\
\text { feedback }\end{array}$ & $840 \mathrm{~s}$ & $0 \%$ & quickly & $\begin{array}{c}2680 \mathrm{~s} \text { 、 } \\
0.97\end{array}$ & $3100 \mathrm{~s}$ \\
\hline Feedforwad & $1265 \mathrm{~s}$ & $9.8 \%$ & slowly & $2930 \mathrm{~s} 、$ & $3570 \mathrm{~s}$ \\
feedback & & & & 0.96 & \\
\hline
\end{tabular}

Table 5. Feature Comparison Table of Figure 5

\begin{tabular}{cccccc}
\hline & $\begin{array}{c}\text { Adjusting } \\
\text { time }\end{array}$ & overshoot & $\begin{array}{c}\text { Rising } \\
\text { rate }\end{array}$ & $\begin{array}{c}\text { The time } \\
\text { and value of } \\
\text { the highest } \\
\text { after the } \\
\text { interference }\end{array}$ & $\begin{array}{l}\text { The } \\
\text { balance of } \\
\text { time after the } \\
\text { interference }\end{array}$ \\
\hline $\begin{array}{c}\text { Fuzzy } \\
\begin{array}{l}\text { feedforward } \\
\text { feedback }\end{array}\end{array}$ & $670 \mathrm{~s}$ & $0 \%$ & $\mathrm{y}^{\text {quickl }}$ & $\begin{array}{c}3016 \mathrm{~s} 、 \\
1.93\end{array}$ & $4000 \mathrm{~s}$ \\
\hline $\begin{array}{c}\text { Feedforwa } \\
\text { d feedback }\end{array}$ & $1260 \mathrm{~s}$ & $9.7 \%$ & slowly & $3088 \mathrm{~s} 、$ & $4300 \mathrm{~s}$ \\
\hline
\end{tabular}


It can be concluded from Figure 4 and Table 4 that the fuzzy feedforward feedback and feedforward feedback system to reach equilibrium time was 840 s and 1265 s, overshoot was $0 \%$ and $9.8 \%$ respectively, with fuzzy feedforward feedback method has faster rise speed; after the signal of interference channel works, during the period of 2600-2760s feedforward feedback control with fuzzy control decreased faster, and they reach the lowest point of time and values were 2680s 0.97 and 2930s 0.96 respectively, and again reached the equilibrium time were 3100 s and 3570s. Simulation results show that feedforward feedback system with fuzzy control regulating time increased by $33.6 \%$ compared with feedforward feedback system, no overshoot, with faster reaction rate, when the interference occurs, to return to the equilibrium state and declined from the highest point of the rate increased $55.3 \%$, with relatively good control effect.

It can be concluded from Figure 5 and Table 5 that the fuzzy feedforward feedback and feedforward feedback system to reach equilibrium time was $670 \mathrm{~s}$ and $1260 \mathrm{~s}$, overshoot was $0 \%$ and $9.7 \%$ respectively, during the period of 110-500s feedforward feedback with fuzzy control has a faster rise speed compared with feedforward feedback; after joining interference, it's obvious that the feedforward feedback with fuzzy control has faster reaction rate during 2600-3000s to interference, better follow effect, they reach the peak corresponds to time point and values were 3016s 1.93 and 3088s 2.03 , has faster decline rate during 3100-3300s, feedforward feedback had been below the set value during 3600-4300s, again reached the equilibrium time was 4000s and 4300s. Simulation results show that feedforward feedback with fuzzy control rise rate up $46.8 \%$ increased rate compared with the general feedforward feedback, reached the steady time is short, no overshoot, and had sensitive reaction rate for interference of signal source, from the highest point to set value decline rate increased by $7.6 \%$, has good inhibitory effect on the interference and good response ability.

\section{Conclusion}

In this article, the feedforward feedback method with fuzzy control is proposed based on the characteristics of the large time delay and large inertia system. Simulation results show that the control method not only has the fast response and high tracking accuracy of the feedforward control, but also has the simple structure and high precision of the PID control, also has the flexibility and does not depend on the specific model of the fuzzy control. Successfully compensate for the deficiency of conventional PID controller, realize adaptive adjustment of the PID parameters. Overshoot is $0 \%$, and rising rate faster, reach the set value requires less time, has good following characteristics and inhibition no matter joining the interference in the input or interference channel, reach the equilibrium value require less time compared with feedforward feedback, has good robustness and adaptive ability, has good control effect for control system with large time delay.

\section{Acknowledgements}

The work is supported by National Science and Technology Project (2014BAF11B01), Fundamental Research Funds for the Central Universities(2572015BB22). 


\section{References}

[1] Z. W. Zhu, Q. X. Zhang and J. Xu, "Journal Nonlinear dynamic Characteristics and optimal control of a giant magnetostrictive film-shaped memory alloy composite plate subjected to in-plane stochastic excitation", Chinese Physics B. vol. 8, no. 23, (2014).

[2] S. Y. Wang, Y. Shi and Z. X. Feng, "J. A Method for Controlling a Loading System Based on a Fuzzy PID Controller", Mechanical Science and Technology for Aerospace Engineering, vol. 1, no 30, (2011).

[3] L. B. Zhang, Y. P. You and T. Wu, "J. Research on Positioning Servo Control Strategies of a Computerized Numerical Control System", China Mechanical Engineering, vol. 23, (2012).

[4] Z. H. Ma, C. L. Liu and P. A. Kai, "J. Control of Dead-time Systems Based on Disturbance Compensation", Information and Control, vol. 5, no. 42, (2013).

[5] D. G. Jiang, "J. The Temperature Control of Greenhouse Based on Novel PID Controller", Research and Exploration in Laboratory, vol. 1, no. 34, (2015).

[6] S. Li, Z. X. Wang, G. Q. Wang and D. G. Wu, "J. PID Neural Network Sliding-mode Controller for Three-level Offshore Wind Power VSC-HVDC Converter”, Proceedings of the CSEE, vol. 4, no. 32, (2012).

[7] H. A. Yousef and M. Hamdy, "J. Observer-based Adaptive Fuzzy Control for a Class of Nonlinear Time-delay Systems", International Journal of Automation and Computing, vol. 4, no. 10, (2013).

[8] G. T. Chen, C. Q. Liu, Q. Sun, Y. R. Zhong and Z. G. Yin, "J. A Current Control Strategy Based on Feedforward Control for Plasma", Transactions of China Electrotechnical Society, vol. 8, no. 29, (2014).

[9] T. Goranka, B. Sanjin and Z. Roberto, "J. Comparative Analysis of PSO Algorithms for PID Controller Tuning", Chinese Journal of Mechanical Engineering, vol. 5, no. 27, (2014).

[10] Z. Y. Shi, T. M. Wang, D. Liu, C. Ma and X. N. Yuan, "J. A fuzzy PID-controlled SMA actuator for a two-DOF joint", Chinese Journal of Aeronautics, vol. 2, no. 27, (2014).

[11] D. L. Liu, Y. F. Cui, X. D. Zhao, M. B. Chen, J. Fuzzy Control of Speed of Permanent Magnet Synchronous Motor Based on Backstepping Control. Transactions of China Electrotechnical Society. 11, 29 (2014)

[12] J. P. Cao, S. K. Jeong and Y. M. Jung, "J. Fuzzy logic controller design with unevenly-distributed membership function for high performance chamber cooling system", Journal of Central South University, vol. 7, no. 21, (2014).

[13] C. Yao, X. B. Ruan, W. J. Cao and P. L. Chen, "J. An Input Voltage Feedforward Control Strategy for Two-switch Buck-Boost DC-DC Converters", Proceedings of the CSEE, vol. 21, no. 33, (2013).

[14] Z. H. Jiang, X. M. Li and W. H. Gui, "J. All parameters adaptive predictive control strategy for long time-delay system", Journal of Central South University(Science and Technology). 1, 43 (2012)

[15] B. You, H. Peng, M. Y. Hu, Z. X. Xiong, J. Design of Temperature Control System in Causticizing Process Based on Fuzzy Feed-forward Feed-back Control. Transactions of China Pulp and Paper, vol. 3, no. 28, (2013).

[16] L. J. Wang, C. N. Tong, Q. Li, Y. X. Yin, Z. Q. Gao and Q. L. Zheng, "J. Practical active disturbance rejection solution for monitoring automatic gauge control system with large time-delay", Control Theory \& Applications, vol. 3, no. 29, (2012).

\section{Authors}

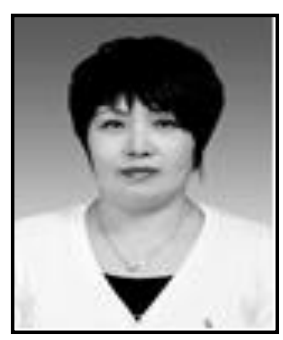

Honge Ren, she was born in 1962. She received the Ph.D. degree from Northeast Forestry University, China, in 2009. She is currently professor of information and computer engineering college at school of Northeast Forestry University, supervisor of Dr. Her main research interests include the pattern recognition and intelligent control.

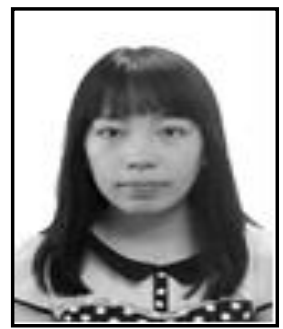

Yali Chen, she was born in 1991. She received the bachelor's degree from Northeast Forestry University, China, in 2014. Now she is studying in Northeast Forestry University for the master's degree. Her main research interests include the pattern recognition and intelligent control. 


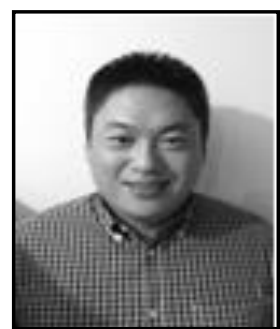

Ming Yu, he was born in 1981. He received the master's degree from Northeast Forestry University, China, in 2006. Now He is studying in Northeast Forestry University for the Ph.D. de gree. His main research interests include the pattern recognition and intelligent control. 